\title{
Effect of Assertiveness Skills on Job Burnout
}

\author{
Aqsa Butt ${ }^{1 *}$, Zahid Mahmood Zahid ${ }^{2}$ \\ ${ }^{1}$ Independent Researcher \\ ${ }^{2}$ MS (Marketing) \\ University of Agriculture Faisalabad, Pakistan \\ *Email: lamaqsabutt@gmail.com
}

Keywords: Assertiveness skills, job burnout, SPSS 22, Regression, Regulation

\begin{abstract}
Assertiveness is the ability to express oneself and one's rights without violating the rights of others. The need for assertiveness is widely acknowledged in different work settings, and in order to manage the stress of working as part of a team every day, one has to become assertive. The purpose of present study is to investigate the effect of assertiveness skills on job burnout. The random sampling technique was employed. The data were gathered from 100 respondents. The adapted questionnaire was used. The advanced econometric technique was employed for data analysis. The SPSS 22 was employed as tool for data analysis. The findings of study revealed that assertiveness skills have negative effect on job burnout. With increase the level of assertiveness skills, increase consistency and confidence and reduce conflict and stress leads to decrease burnout. The study also recommends improving the management, regulation and facilities for preventing of risk of job burnout.
\end{abstract}

\section{INTRODUCTION}

In contemporary environments, professionals need to become more aware of how to use assertiveness effectively in their workplaces to manage the challenges they face when dealing with human resources. Communications are one of the most important aspects of social life health and Source of culture and also it is as the background and the basis of promotion and movement of human. If the Communication is not in the right direction, undoubtedly the main bases of life and satisfaction fade. In this respect, effective communication with others is a skill that puts human in a position excellent and makes it easier to achieve success and happy (Bastani, 2008). Effective communication is a relationship that is satisfied both sides. Assertiveness is one of effective communication skills. The personal and professional skills is effected it. In many cases the lack of Assertiveness causes to stress, anxiety, less of productivity, burnout and so on. These people cannot defend themselves, therefore they deal with people passive, regret and shy, also they obey of wants and desires of others. Burnout is potential problem in all the jobs, especially service businesses such as banks (Amiri, etal, 2012). Burnout is attended to researchers and managers because it reduces the productivity and efficiency and can impair family life. People with job burnout may have a negative effect on their coworkers why that may conflict or do not their duties properly (Rasouli, 2013). In the banking system, bank managers are in close communication with their clients, they should have good communication skills with customers and coworkers, Decision making and crisis management, Marketing and sales skills to evaluate new and existing clients, Appropriate planning to attract capital in the bank, Honesty and integrity, be familiar with good financial rules. On the other side, work is in much of aspects of active people life in society. It seems that work activities are an important for mental health. But some researchers assert that sometimes it may be a major source of stress in humans. It means that a job may be source of dissatisfaction and burnout. Study of job burnout is important from two aspects: First, burnout affect on the mental health of employees in the organization. Second, burnout affects the quality of provided services by employees and put it down. Therefore, its understanding and prevention can also raise level of mental health and quality of services (Chavoshi, et al, 2012). Several studies have been done on the relationship between burnout and mental health, which indicates the importance of this issue. Arizi, 
et al (2013), Binabaj and et al (2004) showed that there is statistically significant correlation between mental health and job burnout.

\section{ASSERTIVENESS SKILLS}

Assertiveness is considered to be healthy and desirable behavior for all people who interact in a group situation insofar as it militates against personal powerlessness and can result in personal empowerment and ultimately benefit the group, or workplace as a whole. In the first time Wolpe (1958) introduced Assertiveness. He believes there is mutually contradictory between the assertiveness answers and anxiety and those with learning this behavior can be largely overcome fear. Assertiveness means respect to yourself and others and shows that are equal the importance of ideas, thoughts, beliefs and feelings of other people (Cahamarkoohi \& Amini, 2013). Assertive behavior represents the expression of a person's rights, thoughts and feelings without denying the rights of others (Alberti \& Emmons, 1986). Crosley (1980) and Lee and Crockett (1994) reported that nurses who acquired assertiveness were able to do their work effectively by decreasing stress and improving interpersonal relationships. Previous studies have indicated that in novice nurses assertiveness is significantly related to burnout (Suzuki et al., 2006b), reality shock (Itomine et al., 2006), intention to leave (Suzuki et al., 2005), and commitment to work (Azuma \& Suzuki, 2007). According to Huczynski (2004) a vital component of assertiveness is the principle of self-respect, and in order to build self-respect we need to remind ourselves of our rights, for example our right to communicate. This gives us the confidence to stand up for ourselves whilst at the same time remembering that others also have rights. Assertiveness goal is helping to people to change their opinion and Increase their courage to express their thoughts and reasonable manner and thereby to increase their self-confidence. Anxiety and assertiveness in the workplace leads to impairment of job performance, intelligence and learning ability, loss and depression thinking talents. It causes damage to individuals, families and communities (Mehrabi, et al, 2009). Lin (2008) believed assertiveness is skill that reinforces self-efficacy and self-control in a way Self-efficacy and selfcontrol. The skill is the best way to cope with the anger and satisfying communication with others that need to knowledge, prudence, negotiation and flexibility. Khodabakhshi and et al (2015) in their research showed assertiveness skills are strategies for conflict resolution, assertive communication and the development of personal communication in the workplace. More researchers have defined assertiveness as preferences, desires, the rights and express their emotions. In the point of view, the two major categories of non-assertive behavior are namely passive and aggressive behaviors. In total, assertiveness is one of component of interpersonal skills and have important role in improvement of mental health (Seyedfatemi and et al, 2013).

Mastrez's perspective, assertiveness includes the following components: strongly reject: people rejects the demands imposed by others as friendly community. Strongly express: in the way, people have the ability to express positive emotions such as gratitude from others, expressing love and affection and praise. Strongly Request: in the way of people have the ability to express and discuss requests from others to facilitate individual needs or achieve their aims (Rahimianbogar, 2008).

\section{JOB BURNOUT}

Burnout is a psychological syndrome of exhaustion, cynicism, and inefficacy, experienced by otherwise psychologically healthy individuals in response to chronic job stressors (Leiter \& Maslach, 2004). Leiter and Maslach (1988) have proposed a model of the burnout process, in which lack of coping ability and social support together with an increasing workload and personal problems tend to cause tiredness. Tiredness causes cynicism, which finally results in burnout. They conclude that the decreasing commitment to co-workers causes resignation and leave-taking (Maslach et al., 2001). In recent years, job burnout is attended by behavioral science and management thinkers. Also the lethargy, sluggishness and lethargy are called burnout. Pines \& Keinan believed that burnout mainly in the field of research related to stress and sense. Also, job 
burnout is an important factor that affects performance and productivity of the organization and is a metaphor used to describe the mental state employees (faghihi and et al, 2012). A wide variety of predictors of burnout have been examined, with much of the research focusing on aspects of the work environment and characteristics of the job. For example, supportive work environments have been associated consistently with lower levels of burnout (Boyer \& Bond, 1999; Carney et al., 1993; Lee \& Ashforth, 1996; Leiter \& Maslach, 1988). Personal characteristics also have been studied, including demo- graphics, personality traits, and job expectations. The most important visible effects job burnout is decline in performance and quality of service. Chernise (1980) is defined burnout losing enthusiasm, excitement and a sense of responsibility towards job (Chavoshifar and et al, 2012). Hanani and et al (2012) stated that burnout is one of effects of related to work which has been considered in recent years. Lakriz defined burnout to describe human responses to the stresses experienced during work that includes psychological reactions when faced with the job stress (Amiri and et al, 2012).

Masalach (2001) divided job burnout to two categories: situational and personal factors such as demographic characteristics, personality traits and coping styles. Situational factors such as job characteristics, expectations, motivation and job resource (Safari and godarzi, 2010). Gelard believes that job burnout include attitude to work and quality of work and satisfaction. Totally job burnout in banking systems which are in direct contact with the client can reduce the efficiency and quality of services. Therefore, effects of assertiveness skills on job burnout of managers of banks are important and based on research hypotheses were as follows:

\section{HYPOTHESES}

1. Assertiveness Skills have effect on job burnout of managers of banks.

2. Strongly request has effect on job burnout of managers of banks.

3. Strongly reject has effect on job burnout of managers of banks.

4. Strongly express has effect on job burnout of managers of banks.

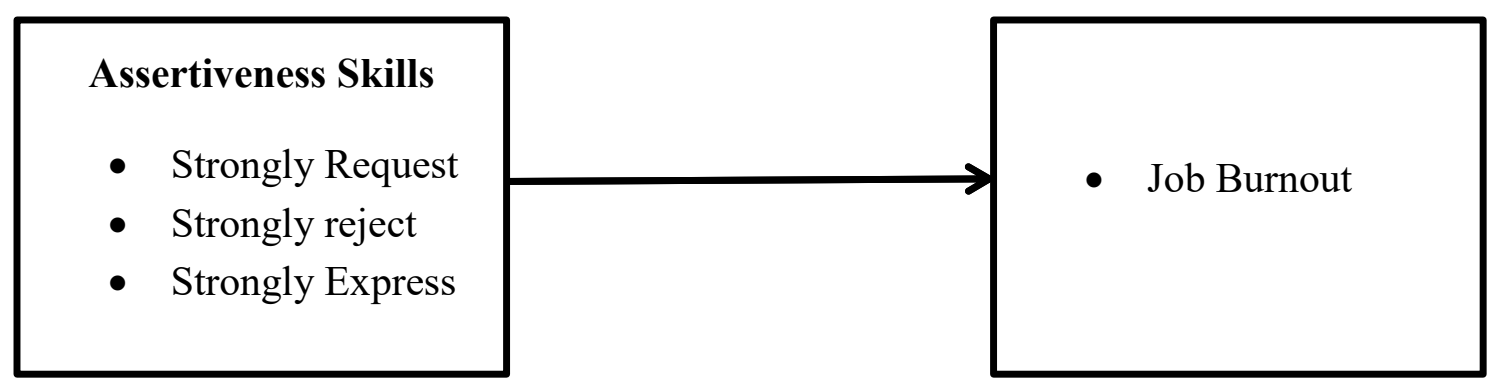

\section{METHODOLOGY}

The purpose of this study is to explore the effect of Assertiveness Skills on job burnout of managers of banks in Pakistan. This study is descriptive and correlation. A total of 100 managers were randomly selected from two banks of Pakistan i.e. Bank Alfalah and Meezan Bank In the study, assertiveness skills and job burnout have adapted from different sources. Assertiveness Skills scale was adapted from Masterze. Job burnout scale was adapted by Gldard. All the questionnaires were rated by five-point Likert scale. The alpha values were used to estimate reliability of scales. Alpha reliability was as 0.85 for Assertiveness Skills and 0.80 for job burnout. The descriptive statistics, multiple regression and Pearson correlation methods were employed to analyze the data.

\section{FINDINGS OF STUDY}

The result of descriptive study about underlying variables that drown from SPSS 22 revealed that $70 \%$ of the respondents were male and $30 \%$ were female. The age of $18 \%$ of the respondents was $30-40,72 \%$ was $41-50 ; 10 \%$ was more than 50 years old. $5 \%$ of the respondents had Diploma, $30 \%$ of the respondents had Bachelor, $60 \%$ Master, and 5\% PhD. Also, the results of descriptive 
statistic showed that average Assertiveness Skills in studied university was 4.85 and job burnout was 5.24 (table 1,2)

\begin{tabular}{|c|c|c|c|c|}
\hline \multicolumn{5}{|c|}{ Table 1. Descriptive statistic of Assertiveness Skills } \\
\hline & Frequency & Cumulative & Percentage & Cumulative frequency percent \\
\hline Never & 0 & 0 & $0 \%$ & $0 \%$ \\
\hline Less & 1 & 1 & $1 \%$ & $1 \%$ \\
\hline Average & 80 & 81 & $80 \%$ & $81 \%$ \\
\hline More & 19 & 100 & $19 \%$ & $100 \%$ \\
\hline Much more & 0 & 100 & $0 \%$ & $100 \%$ \\
\hline Total & 100 & & $100 \%$ & $100 \%$ \\
\hline Average & & & & 4.85 \\
\hline
\end{tabular}

\begin{tabular}{|c|c|c|c|c|}
\hline \multicolumn{5}{|c|}{ Table 2. Descriptive statistic of Job Burnout } \\
\hline & Frequency & Cumulative & Percentage & $\begin{array}{c}\text { Cumulative frequency } \\
\text { percent }\end{array}$ \\
\hline Never & 0 & 0 & $0 \%$ & $0 \%$ \\
\hline Less & 1 & 1 & $1 \%$ & $1 \%$ \\
\hline Average & 80 & 81 & $80 \%$ & $81 \%$ \\
\hline More & 15 & 96 & $15 \%$ & $96 \%$ \\
\hline $\begin{array}{c}\text { Much } \\
\text { more }\end{array}$ & 4 & 100 & $4 \%$ & $100 \%$ \\
\hline Total & 100 & & $100 \%$ & $100 \%$ \\
\hline Average & & & & 5.24 \\
\hline
\end{tabular}

Inferential Statistic and regression Model in SPSS software were used to examine the main hypothesis. Table 3 presents the results of multiple regression analysis that shows the basic assumptions of the model is established. $\mathrm{T}$ test and $\mathrm{P}$-value $=0.000<0.05$ showed that there is Significant adverse effect between Assertiveness Skills and job burnout (table 3); also the results of the breakdown of the two banks are presented in table 4 .

\begin{tabular}{|l|r|r|r|r|r|r|}
\hline \multicolumn{7}{|c|}{ Table 3. Result of multiple regression analysis } \\
\hline & $\begin{array}{l}\text { correlation } \\
\text { coefficient }\end{array}$ & $\begin{array}{l}\text { Standard } \\
\text { deviation }\end{array}$ & T & P value & $\begin{array}{l}\text { Correlation } \\
\text { Coefficients }\end{array}$ & \multicolumn{2}{|c|}{$\mathbf{R}^{\mathbf{2}}$} \\
\hline Fixed & 6.15 & 0.541 & 10.541 & 0.000 & \multirow{2}{*}{0.192} \\
\cline { 1 - 5 } $\begin{array}{l}\text { Assertiveness } \\
\text { Skills }\end{array}$ & -0.854 & 0.114 & -3.456 & 0.000 & -0.345 & \\
\hline
\end{tabular}

\begin{tabular}{|l|l|l|}
\hline \multicolumn{4}{|c|}{ Table 4. The results for comparing two banks } \\
\hline & Bank Alfalah & Meezan Bank \\
\hline Coefficients & -0.451 & -0.41 \\
\hline $\mathrm{p}$ Value & 0.002 & 0.004 \\
\hline
\end{tabular}

For investigating the impact dimensions of Assertiveness Skills on job burnout was used to multiple regression analysis. The results in table 5, 6 showed there is significant adverse effect between strongly reject and job burnout (P-value $=0.000<0.05)$. 


\begin{tabular}{|c|c|c|c|c|c|c|}
\hline \multicolumn{7}{|c|}{ Table 5. Result of multiple regression analysis } \\
\hline & $\begin{array}{l}\text { correlation } \\
\text { coefficient }\end{array}$ & $\begin{array}{l}\text { Standard } \\
\text { deviation }\end{array}$ & $\mathbf{T}$ & P value & $\begin{array}{l}\text { Correlation } \\
\text { Coefficients }\end{array}$ & $\mathbf{R}^{2}$ \\
\hline Fixed & 5.012 & 0.423 & 13.123 & 0.000 & \multirow{2}{*}{-0.452} & \multirow[t]{2}{*}{0.381} \\
\hline Strongly Reject & -0.475 & 0.115 & -4.121 & 0.000 & & \\
\hline \multicolumn{7}{|c|}{ Table 6. The results for comparing two banks } \\
\hline \multicolumn{4}{|c|}{\begin{tabular}{l|l} 
& Bank Alfalah \\
\end{tabular}} & \multirow{2}{*}{\multicolumn{2}{|c|}{ Meezan Bank }} & \\
\hline Coefficients & & & -0.542 & & & -0.404 \\
\hline p Value & & & 0.001 & & & 0.003 \\
\hline
\end{tabular}

The results in table 7 and 8 showed there is Significant adverse effect between strongly request and job burnout $(\mathrm{P}$-value $=0.000<0.05)$.

\begin{tabular}{|l|r|r|r|r|r|r|}
\hline \multicolumn{7}{|c|}{ Table 7. Result of multiple regression analysis } \\
\cline { 1 - 5 } & $\begin{array}{l}\text { correlation } \\
\text { coefficient }\end{array}$ & $\begin{array}{l}\text { Standard } \\
\text { deviation }\end{array}$ & T & P value & $\begin{array}{l}\text { Correlation } \\
\text { Coefficients }\end{array}$ & \multirow{2}{*}{$\mathbf{R}^{\mathbf{2}}$} \\
\cline { 1 - 6 } Fixed & 4.315 & 0.398 & 12.781 & 0.000 & -0.315 & 0.101 \\
\hline Strongly request & -0.456 & 0.105 & -3.125 & 0.005 & \\
\hline
\end{tabular}

\begin{tabular}{|l|r|r|r|}
\hline \multicolumn{4}{|c|}{ Table 8. The results for comparing two banks } \\
\hline & Bank Alfalah & Meezan Bank & -0.187 \\
\hline Coefficients & -0.195 & 0.045 \\
\hline p Value & & 0.023 & \\
\hline
\end{tabular}

The results in table 9 and 10 showed there is significant adverse effect between strongly express and job burnout $(\mathrm{P}-\mathrm{value}=0.000<0.05)$.

\begin{tabular}{|l|c|r|r|r|r|r|}
\hline \multicolumn{7}{|c|}{ Table 9. Result of multiple regression analysis } \\
\hline & $\begin{array}{l}\text { correlation } \\
\text { coefficient }\end{array}$ & $\begin{array}{l}\text { Standard } \\
\text { deviation }\end{array}$ & T & P value & $\begin{array}{l}\text { Correlation } \\
\text { Coefficients }\end{array}$ & \multicolumn{2}{|c|}{$\mathbf{R}^{\mathbf{2}}$} \\
\hline Fixed & 4.985 & 0.397 & 12.654 & 0.000 & -0.417 & 0.174 \\
\hline Strongly express & -0.574 & 0.125 & -4.354 & 0.000 & & \\
\hline
\end{tabular}

\begin{tabular}{|c|c|c|}
\hline \multicolumn{3}{|c|}{ Table 10. The results for comparing two banks } \\
\hline & Bank Alfalah & Meezan Bank \\
\hline Coefficients & -0.497 & -0.389 \\
\hline $\mathrm{p}$ Value & 0.001 & 0.003 \\
\hline
\end{tabular}

\section{CONCLUSION}

The purpose of present study is to explore the effect of assertiveness skills on job burnout. The bank managers were selected as sample of study. The findings of present study revealed that there is significant adverse relationship between assertiveness skills and job burnout. If the assertiveness skills increase, the job burnout decreases and vice versa. In other words, increasing the level of assertiveness skills, increase confidence and consistency reduce stress and conflict that leads to decrease burnout. Similar results were reported in some studies as Sarminito (2004), gutas (2008), sheikh and esmaili (2011), Safari and godarzi (2010). The findings of present study also revealed that there is significant adverse effect between dimensions of assertiveness skills and job burnout. Similar results were reported in Lazarus. He believed that in order to reduce job burnout can be corrected individual's inappropriate relationships with methods of reject requests. But Malekara( 2009) is countercurrent with this research. It is also noticed that banks have major role in 
economy of any country and managers have vital role in operating a bank who serve customers and people. Therefore it recommends improving the management, regulation and facilities for preventing of risk of job burnout. Also, due to the stress of managers of banks is recommended by teaching the skills of time management, to improve performance and increase job satisfaction and job burnout reduce. Also the ability to strongly request in mind of managers of bank branches is empowered to realize their importance and reduce the risk of job burnout.

\section{References}

[1] Alberti, R. E. \& Emmons, M. L. (1986). Your Perfect Right: a Guide to Assertive Behavior (4th ed., pp. 31-32). San Luis Obispo, CA: Impact Publishers.

[2] Amiri M, et al .2012. The study of Job burnout among Bank staff and presenting alternatives to improve the situation, the journal of business management, 3(7).

[3] Arizi H.2013. Meta-analysis of research on the relationship between job burnout and mental health. Journal of Social Welfare, 13(48).

[4] Bahri N.2010. the effect of assertiveness training on self-esteem counseling by female students, the journal of Peiknoor, 8(1).

[5] Bastani Gh. 2008. Principles and techniques for effective communication with others. Tehran. Published Ghoghnoos

[6] Chamarkoohi R, Mohamadamini Z. 2013. The effectiveness of stress reduction to improve of mindfulness and increase assertiveness in students with test anxiety. Journal of School Psychology, 1(3).

[7] Chavoshifar J, et al. 2012. Evaluate and predict the factors affecting job burnout operational areas Offshore Oil Company. The journal of management and human resource, 16

[8] Faghihi A, et al.2012. The relationship between organizational intelligence and job burnout, Journal of New Psychology Industrial /Organizational, 2(7).

[9] Hanani M. 2012. The surveying the relationship between burnout and demographic characteristics of cashiers in state banks, The journal of Feiz, 15(1)

[10] Kalliath, T. \& Morris, R. (2002). Job satisfaction among nurses - a predictor of burnout levels. Journal of Nursing Administration, 32, 648-654.

[11] Kilkus, S. P. (1993). Assertiveness among professional nurses. Journal of Advanced Nursing, $18,1324-1330$.

[12] Khodabakhshi A, et al.2015. The effectiveness of group assertiveness skills on factors related to students' mental health, Journal of Psychiatric Nursing, 1 (4).

[13] Lin Y, Shiah Y, et al .2008. Evaluation of an assertiveness training program on nursing and medical students' assertiveness, self-esteem and interpersonal communication satisfaction. Nurse education today. 24(8): 656-665.

[14] Malekara B.2010. The investigate the relationship between time management and job burnout of employees of the State Tax Administration of West Azerbaijan in fiscal year 1388. Journal of Taxation, 4(52)

[15] Maslach C, Leiter MP.2005. Reversing Burnout: How to rekindle your Passion for your work. Standford Social Innovation Review, Graduate school of Business.

[16] Mehrabizade $\mathrm{H}$, et al.2010. The impact of assertiveness training on social skills, social anxiety and academic performance of female students, Journal of Behavioral Sciences, 3(1).

[17] Rahimianbogar E, et al.2008. Investigate the effect of assertiveness techniques on social adjustment. The journal of educational innovations, 23(6). 
[18] Rasouli Z.2013. Relationship between job stress and job burnout in the productivity of pilots. Journal of Military Medical Sciences of Iran, 1

[19] Safari Sh, Ghodarzi H.2010. Investigate the relationship between personality characteristics and job burnout among faculty and staff of Azad University of Azadshahr. Journal of Educational Leadership and Management, 3(3).

[20] Seyedfatemi N, et al. 2013. The surveying correlation Understanding of ability of problem solving with assertiveness skills of nursing students. Journal of School of Nursing and Midwifery of Tehran University of Medical Sciences, 19(3).

[21] Seyedgharaini Kh, seyedabaszade A. 2009. The surveying the relationship between leadership styles and job burnout among high school teachers in the academic year 86-85. Journal of Education, 97 .

[22] Sheykhsari H, Esmailifar N. 2011. The relationship between job burnout and the five-factor personality types among the staff of Tehran Municipality. Journal of New Psychology Industrial /Organizational, 1(4).

[23] Tobaee, Sh and A.S. Sahraian, 2006 Comparison of burnout among nurses, surgical, psychiatric and burn, Knowledge Horizons, Journal of Faculty of Medical Sciences and Health Services Gonabad, 12(4): 40-45.

[24] Tavakoli, S.h., A. Lumley Mark, M. Hijaz Alaa, M. Slavin-Spenny Olga, P. Parris George, 2009. Effect of assertiveness training and expressive writing of acculturative stress in international student. A randomized trial. Journal Counseling Psychology, 56(4): 567-590.

[25] Tomaka, J., R. Palacios, K.T. Schneider, M. Colotla, J.B. Concha, M.M. Herrald, 1999. Assertiveness predicts threat and challenge reactions to potential stress among women. J Pers Soc Psychol., 76(6): 1008-1021. 